\title{
Calcium Phosphate Crystal Measurement
}

National Cancer Institute

\section{Source}

National Cancer Institute. Calcium Phosphate Crystal Measurement. NCI Thesaurus. Code C74671.

The determination of the amount of calcium phosphate crystals present in a sample. 